\title{
Competitiveness of Early Potato Production in Two-Crop Culture
}

\author{
Levshin A.* \\ Russian State Agrarian University - Moscow Timiryazev \\ Agricultural Academy \\ Moscow, Russia \\ Alev200151@rambler.ru \\ Ivashova O. \\ Russian State Agrarian University - Moscow Timiryazev \\ Agricultural Academy \\ Moscow, Russia \\ olga300377@yandex.ru
}

\author{
Gasparyan I. \\ Russian State Agrarian University - Moscow Timiryazev \\ Agricultural Academy \\ Moscow, Russia \\ irina150170@yandex.ru \\ Gasparyan Sh. \\ Russian State Agrarian University - Moscow Timiryazev \\ Agricultural Academy \\ Moscow, Russia \\ schagen2010@yandex.ru
}

\author{
Deniskina N. \\ Russian State Agrarian University - Moscow Timiryazev Agricultural Academy \\ Moscow, Russia \\ nategor@yandex.ru
}

\begin{abstract}
The improvement of the competitiveness of agricultural products and ensuring food security of the country are the most important tasks of agriculture. All the changes due to the introduction of new cultivation technologies or improvement of old ones should be justified and expedient. Increasing potato production in Russia to provide the population with food and for export to European countries through the use of a two-crop culture is promising. This technology is used mainly in the southern regions of the country, but due to recent climate warming, namely, an increase in the growing season, the sum of active temperatures can be used in the middle zone. The economic and energy efficiency of early potato production in twocrop culture was carried out. The cultivation technology is standard. The experiments were carried out three times. Variants in the experiment were placed by a randomized method. The area of one experimental plot is $25 \mathrm{~m}^{2}$. We used the following varieties: Luck, Zhukovsky early, Bullfinch, Red Scarlet and Meteor. Planting dates - when warming the soil to $6 \ldots 8{ }^{\circ} \mathrm{C}-$ May 4. The second landing was carried out on July 15 . The first harvest was carried out on July 15, and the second harvest on September 25. One crop option was harvested on August 25th. The production of early potatoes in a two-crop crop is efficient. Proof of this is an increase in total productivity by $1.54 \mathrm{t} \cdot \mathrm{ha}^{-1}$, revenue from products sold and net income by 243.68 thousand rubles, as well as an increase in profitability by $32.6 \%$. The efficiency of potato production in two-crop crops is also evidenced by the energy efficiency coefficient, which is higher than 0 and amounts to 0.81 .
\end{abstract} ratio.

Keywords - potato, yield, profitability, cost, net energy

\section{INTRODUCTION}

The Food Security Doctrine of the Russian Federation provides for food independence. "The only way to keep the state in a state of independence from anyone is agriculture. Have at least all the riches of the world, if you have nothing to eat - you depend on others. Trade creates wealth, but agriculture provides freedom", wrote Jean-Jacques Rousseau (1738) [1].

For this, it is necessary to stimulate the growth of agricultural production, increase the competitiveness of agricultural products through the development and application of new cultivation technologies or improve them, as well as the introduction of digital systems, modern methods of genetics, machinery and equipment, etc.

The introduction of new technology into production or its improvement is possible only when the products on the market are competitive. In order to do this, it is necessary to produce products that will have a low cost, and their production will be cost-effective even in adverse conditions. Therefore, all changes in crop cultivation technology should be appropriate and justified.

Potato is a valuable food product for almost the entire population of the world, as it is one of the sources of calories for most of the population and is the third crop in the world after rice and wheat [2]. Its gross production is over 370 million tons [3] and is cultivated in a variety of ways, from the use of high-performance machines to the use of primitive technologies in developed countries.

Demand for potatoes continues to grow worldwide. The main supplier and consumer is China, which plans to increase by another $50 \%$, as domestic demand for this product is not saturated [///]. Environmentally friendly products are also gaining popularity, one of its areas is organic farming, which is practiced in 181 countries [4]. The market for the 
consumption of organic products is growing very intensively especially in European countries, production is not in time and the most promising in terms of supply is Russia. Therefore, the increase in potato production in Russia from this point of view is also promising.

Potato cultivation in Russia is possible in any climatic zones, as this crop is very plastic and undemanding in comparison with other crops and has great potential for further increase in production. It provides more nutrients per unit area: the potential potato yield is high $[5,6]$, and according to some scientists it can reach up to $1000 \mathrm{t} \cdot \mathrm{ha}^{-1}$. It is also possible to increase productivity by cultivating it in a two-crop culture, due to climate warming, especially in the northern regions of Russia [2]. Such landings are mainly located in the southern regions of our country, Ukraine, Central Asia [7]. But in recent years, the receipt of two harvests of early potatoes has become possible in the conditions of the Moscow region $[2,4]$. In this case, the total crop yield increases. The aim of our work is the economic and energy rationale for the cultivation of early potatoes in a two-crop culture.

\section{MATERIAL AND METHODS}

The effect of early potato productivity in a two-crop culture on energy and economic efficiency was studied. Studies were carried out in 2018-2019 years on the site of the laboratory of vegetable growing RSAU-MTAA named after K.A. Timiryazev. The cultivation technology is standard. The soil is highly cultivated sod-podzolic. The experiments were carried out three times. Variants in the experiment were placed by a randomized method. The area of one experimental plot is $25 \mathrm{~m}^{2}$. Used varieties: Luck, Zhukovsky early, Bullfinch, Red Scarlet, Meteor. Planting dates - when warming the soil to $6 \ldots 8^{\circ} \mathrm{C}-$ May 4 . The second landing was carried out on July 15. The first harvest was carried out on July 15, and the second harvest on September 25. One crop option was harvested on August 25th. When caring for crops, modern pesticides were used in the fight against late blight and the Colorado potato beetle. The cost of planting material amounted to 10 rubles $/ \mathrm{kg}$. The cost of fertilizers, plant protection products, fuels and lubricants, electricity was taken at the average market price in 2018-2019. When determining energy consumption, the methodological recommendations of G. Pospypanov were used. and Dolgodvorova V.E. (1995), teaching aid Matyuk N.S., Polina V.D. (2013) and study guide Sutyagina V.P., Tulikova A.M., Sutyagina T.I. (2008) [8, 9]. Economic indicators were calculated according to the standard method [10-12].

\section{RESEARCH RESULTS}

The demand for potatoes is growing, and world production is growing. According to the FAO, in 2019, 394 million tons were collected in the world, which is approximately 100 million tons more than in 1961. Potato production has increased in all countries. The main producers at the moment are China, India and Russia. China produces 99.1 million tons,
India -43.8 , Russia -31.1 , in recent years Ukraine adjoins Russia - 21.8 million tons. The volume of production in Russia is three times less than China. Intense growth has occurred in the Asian hemisphere. In 1961, the proportion of Asian potato production was only $8.6 \%$, in recent years $50.6 \%$, the proportion of European potatoes fell: it was $82 \%$, and it became $31.2 \%$. In recent years, there has been a significant increase in potato production in Africa (from $1 \%$ to $6.5 \%)$ [3].

Gross production is primarily associated with the planted area, but they remained within 20 million hectares. In our country, the area under the potato did not undergo significant changes, which in 1961 planted potatoes amounted to 22.0 million hectares, currently 20 million hectares. China has 5.8 million ha, India -2.1 , Ukraine -1.3 million ha [3]. The increase in gross production is associated with increased yields.

Gross production is primarily related to the area of landings, but they remained within 20 million ha. China has 5.8 million ha, India -2.1 , Russia - 2.0, Ukraine -1.3 million ha [3]. The main indicator of agricultural production efficiency is crop productivity. According to the FAO, potatoes are the highest-yielding crops compared to corn, rice, soy and wheat, but over the past 50 years, the yields of these crops have grown quite significantly, and the average yield in the world of potatoes has grown by $46.2 \%$ [13-14]. Potato yields have been increased worldwide (from 12.2 to $19.6 \mathrm{t} \cdot \mathrm{ha}^{-}$ ${ }^{1}$ ), with high average yields in Germany at $44.4 \mathrm{t} \cdot \mathrm{ha}^{-1}$, in the Netherlands at $42.0 \mathrm{t} \cdot \mathrm{ha}^{-1}$, and the United States and New Zealand have a global rating of $49.0 \mathrm{t} \cdot \mathrm{ha}^{-1}$. [15]. High yields are observed in Africa: South Africa - 36.1 t $\cdot \mathrm{ha}^{-1}$, Algeria 30.6, Egypt - 27.2, Mali - 20.0 t $\cdot$ ha $^{-1}$ [3]

The growth was caused by new mechanized technologies, the correct selection of varieties, the use of fertilizers, etc., as well as government support, but in some countries there is a system for the parallel cultivation of potatoes and rice, as well as simultaneous cultivation between crops of corn and soybeans.

In our country, the yield did not increase much compared to other countries: in 1961, the average potato yield was $12.2 \mathrm{t} \cdot \mathrm{ha}^{-1}$, in recent years, the yield was $19.6 \mathrm{t} \cdot \mathrm{ha}^{-1}$, that is, growth was only $60 \%$. This is primarily due to the fact that large specialized agricultural enterprises for the cultivation of potatoes are becoming less and less, and the share of peasant (farm) and personal subsidiary plots is increasing.

In Russia, commodity production carried out by agricultural enterprises is about $56 \%$, the rest of the production is concentrated in private farms and gardening plots of citizens (Fig. 1). In private household plots and farms, the yield is low, and the level of marketability is also low. This is due to the fact that not always high-quality planting material is used, as well as enough special equipment and modern and innovative cultivation technologies are not used. In addition the diseases and pests prevail. 


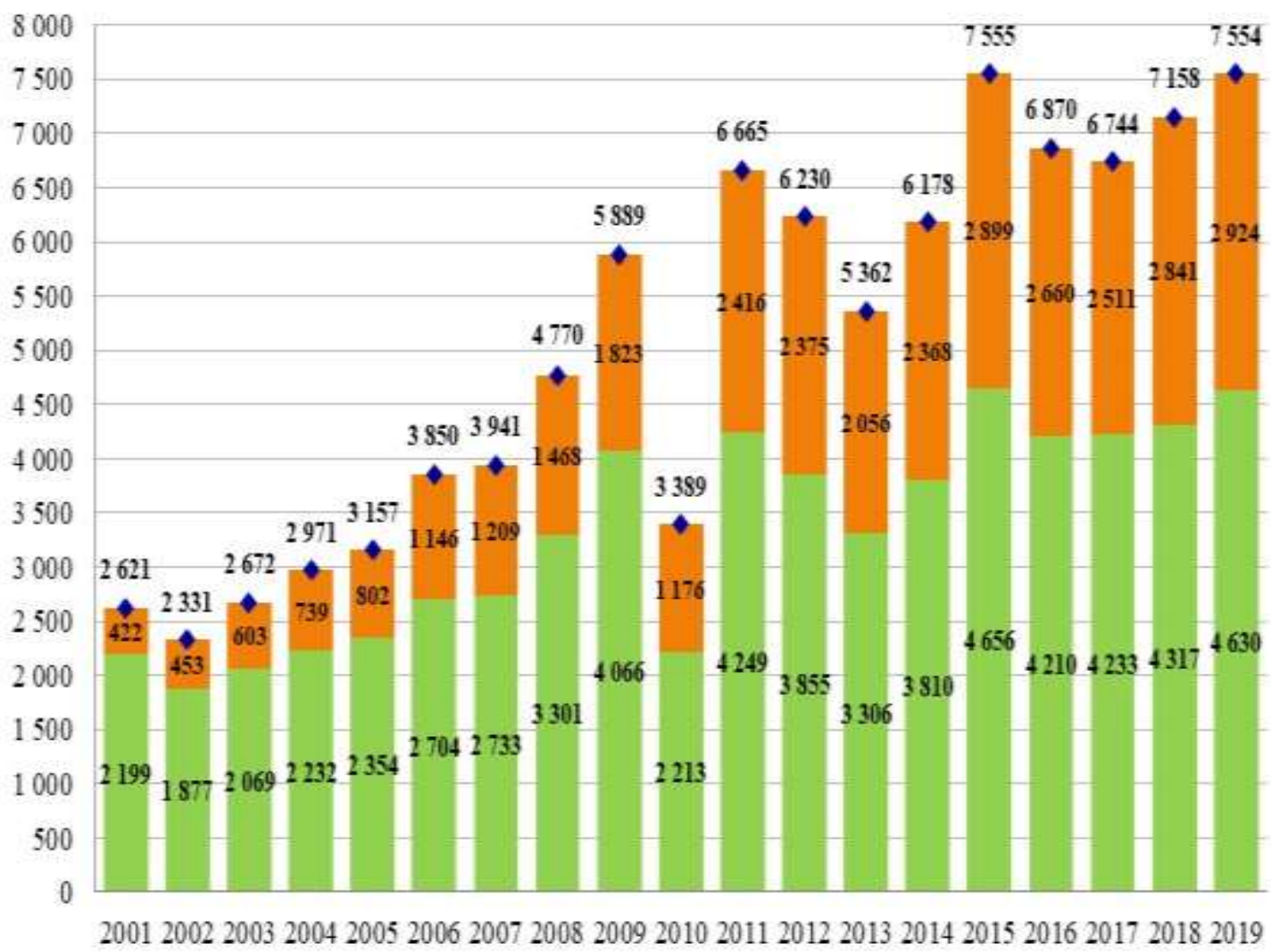

Fig. 1. Dynamics of gross potato harvest in the industrial sector of potato production in 2001-2019, thousand tons (--agricultural enterprises, -- peasant farms)

For private farms and farms with a changing climate, it can be suggested to grow potatoes in a two-crop crop. Such cultivation is common in southern countries, where the growing season is quite large. In our conditions the growing season is much shorter. However, according to some scientists, in recent years there has been an increase in the length of the growing season, and the sum of active temperatures in the Moscow region [16]. According to them, the beginning of the growing season is shifted to earlier dates (second decade of April), in rare cases it is observed even in the third decade of March. The end of the growing season also shifts at a later date and ends mainly in the second decade of October. Due to this, the growing season [2] increases. In such cases, it is possible to cultivate potatoes and get two early potato crops on the same field and thereby increase the total yield from one field, arable land is used more efficiently.

TABLE I.

THE AVERAGE YIELD FOR 2018-2019 YEARS

\begin{tabular}{|l|c|}
\hline Experience option & Productivity, t·ha \\
\hline \multicolumn{1}{|c|}{ Landing May 4, cleaning July 15 } \\
\hline Luck & 20.40 \\
\hline Zhukovsky early & 23.70 \\
\hline Bullfinch & 18.12 \\
\hline Meteor & 16.16 \\
\hline \multicolumn{2}{|c|}{ Landing July 15, cleaning September 25 } \\
\hline Meteor & 26.15 \\
\hline \multicolumn{2}{|c|}{ Landing on May 10, cleaning on August 25 } \\
\hline Luck & 31.2 \\
\hline LSD $_{05}$ & 1.26 \\
\hline
\end{tabular}

The experiment was set up where the first crop was harvested on July 15 and new potato plantings were planted on the vacant place, which were harvested later than normal plantings. Early varieties were used, which began to form tubers 10-15 days after germination [6, 7].

It should be noted that with a two-crop crop, the spread of Phytophthora decreases, since it is observed more in the second half of July. By this time, the first crop is harvested; the second is still only in the soil or in the germination phase. There is no strong spread of infection. But it is necessary to pay attention to the distribution of the Colorado beetle. Effective drugs are sufficient and treatment is minimal.

Yields in the first harvesting period (July 15) for almost all varieties were not high (table1). So, the maximum average yield by years was obtained when harvesting in the first period of the Zhukovsky early variety $\left(23.7 \mathrm{t} \cdot \mathrm{ha}^{-1}\right)$, the minimum average yield by years from the Meteor variety $\left(16.16 \mathrm{t} \cdot \mathrm{ha}^{-1}\right)$. But due to the receipt of two crops from one field, the total yield increased almost 1.35-1.59 times, depending on the combination of varieties, since the yield of the Udacha variety when cultivated in the usual way was $31.2 \mathrm{t} \cdot \mathrm{ha}^{-1}$. 
TABLE II. THE ECONOMIC EFFICIENCY OF POTATO PRODUCTION ON AVERAGE FOR 2018-2019 YEARS

\begin{tabular}{|l|l|l|}
\hline Expenditure & 1 crop & 2 crop \\
\hline Productivity, $\mathrm{t} \cdot \mathrm{ha}^{-1}$ & 31.2 & 46.6 \\
\hline Planting material, thousand rubles & 35.00 & 70.00 \\
\hline Fertilizers, thousand rubles & 11.00 & 22.00 \\
\hline Total costs, thousand rubles & 181.00 & 362.00 \\
\hline $\begin{array}{l}\text { Additional costs for additional harvesting, } \\
\text { thousand rubles }\end{array}$ & 1.27 & 17.57 \\
\hline Total direct costs, thousand rubles & 228.47 & 473.04 \\
\hline Revenue from products sold, thousand rubles & 312.00 & 800.25 \\
\hline Net income, thousand rubles & 83.53 & 327.21 \\
\hline Cost price, rub/kg & 7.32 & 10.15 \\
\hline Profitability level, \% & 36.6 & 69.2 \\
\hline
\end{tabular}

Total direct production costs of $30 \mathrm{t} \cdot \mathrm{ha}^{-1} 1$ ha is 227.20 thousand rubles (table 2), according to the farm. With a twocrop culture, there will be additional costs for planting material, fertilizers, soil preparation for the second crop and additional costs for cleaning the additional crop, which are presented in the table. The table also presents the most significant costs for single-crop crops. The wholesale market price according to the data of the Potato Union in September and October is around 10.0 rubles $/ \mathrm{kg}$; the calculation for a single-crop crop was made from these calculations. With a two-crop crop, the first crop was more expensive, since early potatoes at this time of the year are expensive and range from 20 to 80 rubles for $1 \mathrm{~kg}$, depending on the place of sale, for the calculations they took 20 rubles $/ \mathrm{kg}, 20000$ rubles -1 ton. Therefore, the first successful crop was $20.40 \mathrm{t} \cdot \mathrm{ha}^{-1}$ (Table 1), then the revenue amounted to 408 thousand rubles. The second crop was Meteor (Table 1) $26.15 \mathrm{t} \cdot \mathrm{ha}^{-1}$. Usually, in the fall, mostly universal varieties are harvested that are well stored, have high starch content, but the taste is lower than that of table varieties of early ripening. Due to the fact that the early potato has a good taste, delicate skin, harvested later than all the usual potato plantings, it is well sold to the restaurant business and the price can also be high. Therefore, the price of revenue for the second crop is calculated from these conditions (15.0 rubles $/ \mathrm{kg})$ and will amount to 392.25 thousand rubles. Total revenue will amount to 800.25 thousand rubles. Due to the fact that the cost of a single-crop potato crop is lower than with a two-crop culture, the level of profitability is almost two times higher and amounts to $69.2 \%$. Therefore, this technology allows providing the population not only with high-quality domestic products, since table varieties are used specifically for food, but also for agricultural potato producers to have additional revenue and increase production profitability.

In modern conditions, when prices for products, equipment and various materials vary greatly due to economic instability, pandemics, etc., it is possible to use an energy efficiency assessment for a more objective assessment (Table 3-4).

The difference between the energy received and the energy costs of production shows such an indicator as net energy income, it is $18.76 \mathrm{GJ} / \mathrm{ha}$ more with a two-crop culture than with a single-crop crop. The energy efficiency ratio of landings is above 0 in both versions, the technology is energy efficient. But with single-crop crops, the coefficient is higher and amounts to 1.15 , and with two-crop crops -0.81 . Also higher is the energy efficiency. And at the present stage, the energy cost in a two-crop crop is $0.43 \mathrm{GJ} / \mathrm{t}$ of tubers higher. This is primarily due to the early harvesting of the first crop and the cost of production.

TABLE III. TOTAL ENERGY COSTS (MJ / HA) AND ITS STRUCTURE IN THE CULTIVATION OF POTATOES (AVERAGE FOR 2018-19 YEARS)

\begin{tabular}{|l|l|l|}
\hline Types of total energy costs & 1 crop & 2 crop \\
\hline Machines and agricultural implements & 14220 & 25400 \\
\hline Seeds & 14100 & 28200 \\
\hline Mineral fertilizers & 15490 & 30980 \\
\hline fuel and lubricants & 8190 & 14380 \\
\hline Electric power & 320 & 640 \\
\hline Labor costs & 9340 & 15680 \\
\hline Other expenses & 5600 & 5600 \\
\hline Total & 67260 & 120880 \\
\hline
\end{tabular}

${ }^{\text {a. }}$ Excluding buildings and structures

TABLE IV. ENERGY EFFICIENCY OF EARLY POTATO CULTIVATION (AVERAGE FOR 2018-2019 YEARS)

\begin{tabular}{|l|l|l|}
\hline Indicators & 1 crop & 2 crop \\
\hline Total energy spent, GJ/ha & 67.26 & 120.88 \\
\hline Productivity of the main crop, t/ha & 31.2 & 46.6 \\
\hline Received energy from the main products, GJ/ha & 146.64 & 219.02 \\
\hline Net energy coefficient, GJ/ha & 79.38 & 98.14 \\
\hline Energy efficiency ratio of landings & 1.18 & 0.81 \\
\hline Bioenergy coefficient (COP) of landings & 2.18 & 1.81 \\
\hline Energy cost, GJ/t of tubers & 2.16 & 2.59 \\
\hline
\end{tabular}

Thus, a two-yielding potato culture is economically feasible at modern prices, despite the increasing cost, since our calculations are made at the lowest prices. Early production of the first crop is sold at higher prices and is in great demand by the population, during this period there is a lack of products and mainly products that are imported from Egypt or Israel are used. Their prices are 2-3 times higher [17].

Demand is associated with an increase in the urban population and an increase in income, which contributes to a more diverse diet. Fast food enterprises have appeared, the production of semi-finished products and instant products is rapidly developing, where one of the main products is potatoes. The consumer of fresh potatoes is interested in a good appearance, excellent taste, white or yellow flesh (depending on preference), well-digested, without damage, calibrated, not darkening after cooking. In a number of regions, red-tuberous plants, etc. are in great demand. In recent years, the quality of tubers has improved, this is evident when possible in supermarkets, where products of different price categories, various companies, as well as "brand" categories, such as "premium", "organic", "low-calorie", etc. are presented. . Prices can vary significantly, for example, the cost of potatoes from Egypt is 70 rubles, and the cost of "organic" products is 300 rubles, and the market price is 15 rubles. There is an expensive variety of potatoes in the world "La Bonnotte", which costs about 500-600 euros.

The selling price on the potato market is seasonal. At the same time, wholesale and consumer prices differ two or more times (Fig. 2). In the first half of the year, the price depends on the amount of potatoes pledged for storage. The price of products is high, since there are additional costs for storing products. Prices rise until a new crop - almost until 
September. In early August, products of early potatoes of domestic origin appear on the market. But already from the spring early production from abroad arrives at prices that are 2-4 times higher than old potatoes. She holds until September - October. At this time, the market has the lowest prices.

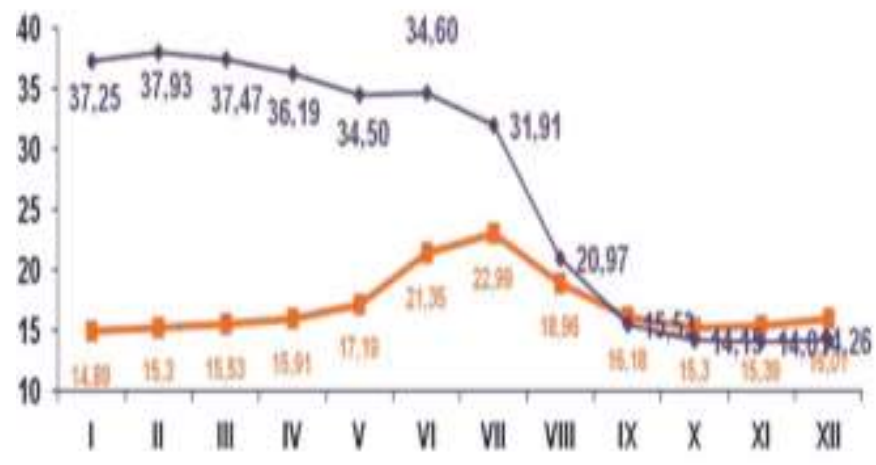

Fig. 2. Average prices of potatoes by months: - producer price; - consumer price

Based on this, the cultivation of potatoes in a two-crop crop for personal subsidiary plots and farms should be interesting; getting the first harvest already on July 15 allows getting the maximum benefit. In addition, the second crop, used in the restaurant business, is interesting and allows more efficient use of agricultural land. However, one cannot overestimate their product capabilities.

Climate change is observed everywhere and has its own adjustments. In the future, new areas of cultivation will appear, the southern regions will reduce the amount of planting due to lack of water supplies, the spread of diseases and pests will increase, etc. It is necessary to look for ways to adapt to changing conditions: to use more stable varieties for growing in these zones, as well as to breed two-crop varieties with a short dormancy period, use various stimulants, etc. getting two harvests has its own costs: we need to think about the correct crop rotation, proper fertilization and an integrated system for protecting potato plants. It is necessary not only to adapt technologies, but also to pursue an investment policy, attracting private and public investments for the development of the potato industry and its support throughout the entire production chain.

\section{CONCLUSIONS}

Early potato production in two-crop cultures is effective, the total yield is increased by $1.54 \mathrm{t} \cdot \mathrm{ha}^{-1}$, revenue from products sold and net income by 243.68 thousand rubles, and profitability is also increased by $32.6 \%$. The efficiency of potato production in two-crop crops is also evidenced by the energy efficiency coefficient, which is 0.81 .

Thus, in the conditions of the Moscow region, obtaining a second crop of potato varieties of early ripening, which in the conditions of market relations will increase the competitiveness of the potato industry and increase its efficiency.

\section{Funding}

The work was carried out in accordance with the thematic plan of research works of Russian State Agrarian University Moscow Timiryazev Agricultural Academy.

\section{Acknowledgments}

The authors would like to thank their colleague for their contribution and support to the research. They are also thankful to all the reviewers who gave their valuable inputs to the manuscript and helped in completing the paper.

\section{Conflict of Interest}

The authors have no conflict of interest to declare.

\section{References}

[1] Chr. Hamman, Deplaire au public: Le cas Rousseau. P., 2012.

[2] O. Ivashova, V. Sychev, M. Dyikanova, A. Levshin, I. Gasparyan, "Two-yieding potato culture in Moscow region", IOP Conf. Ser. Earth and Environmental Sci., p. 012067, 2020. Voronezh State Agrar. Univer. named after Emperor Peter the Great. DOI: 10.1088/17551315/422/1/012067.

[3] FAOSTAT. Retrieved from: http://www.faostat.fao.org/

[4] I.N. Gasparyan, A.G. Levshin, O.N. Ivashova, A.E. Butuzov, M.E. Dyykanova, "Organic technology of cultivation of organic potatoes”, Vest. FGOU VPO MGAU named after V.P. Goryachkin, vol. 6, no. 94, pp. 14-18, 2019. DOI: 10.34677/1728-7936-2019-6-14-18.

[5] Russia in numbers. Brief statistical collection of Rosstat. Moscow, 2017, $511 \mathrm{p}$

[6] M.E. Dyikanova et al., The cultivation of early potatoes, Training manual. Moscow: Publ. House of the Russ. State Auton. and Agricult. Acad. named after K.A. Timiryazev, 2019, 172 p.

[7] B.A. Pisarev, Production of early potatoes. Moscow: Rosselkhoznadzor, 1986, 287 p.

[8] N.S. Matyuk, V.D. Polin, Resource-Saving technologies of soil treatment in adaptive agriculture, Textbook. Moscow: Publ. house of the Russ. state agricult. Acad. named after K. A. Timiryazev, 2013, 222 p.

[9] V.P. Sutyagin, A.M. Tulikov, T.I. Sutyagina, System analysis of energy flows in agriculture, Textbook for graduate design. Tver: AGROSPHERE; Tver state agricult. Acad., 2008, 140 p.

[10] A.V. Shpilko, V.I. Dragaytsev, N.M. Morozov et al., Energy efficiency of agricultural production mechanization. Moscow: All-Russ. Res. Instit. of agricult. Econ., 2001, 346 p.

[11] Methods of research on potato culture. VNIIKH, 1967, $321 \mathrm{p}$.

[12] Methods of research on potato culture, 1967, $352 \mathrm{p}$.

[13] Levshin A.G. "Constructive features of the device to remove the apical shoots of potatoes", pp. 532-537, 2019 [18Th Int. Sci. Conf. Engineering for Rural Development]. (Jelgava, Latvia, 22-24 May 2019). Retrieved from: www.tf.llu.lv/conference/proceedings. DOI: 10.1088/1755-1315/422/1/012067.

[14] World of potatoes. FAO of the UN. Retrieved from: http://www.fao.org/potato-2018/ru/world/europe.html.

[15] Potato. International Potato Centre. Retrieved from https://cipotato.org/crops/potato/

[16] M.D. Pavlova, Workshop on agrometeorology. Leningrad: Hydrometeodat, 1984, $184 \mathrm{p}$.

[17] D. Hassanpanah, Potato Res., no. 53, pp. 383, 2010. Retrieved from: https://doi.org10.1007/s1150-010-9179-5 